\title{
Comparison of plaque and distal-wedge tibial nail in the treatment of extra-articular distal tibia fractures
} \author{
Yılmaz ${ }^{5}$, Levent Demir ${ }^{6}$ \\ ${ }^{1}$ Department of Orthopaedic Surgery, Van Yuzuncu Yil University, Van, Turkey \\ ${ }^{2}$ Department of Orthopaedic, Palandöken State Hospital, Erzurum, Turkey \\ ${ }^{3}$ Department of Orthopaedic Regional, Education and Research Hospital, Van, Turkey \\ ${ }^{4}$ Clinics of Ortopedics and Traumatology, Bursa Cekirge State Hospital, Bursa, Turkey \\ ${ }^{5}$ Erzurum Public Health Directorate, Erzurum, Turkey \\ ${ }^{6}$ Diyarbakir Medoks Hyperbaric Oxygen Treatment Center, Diyarbakır, Turkey
}

Cihan Adanaş ${ }^{{ }^{*}}$, Erdem Yunus Uymur ${ }^{2}$, Sezai Özkan ${ }^{1}$, Şehmuz Kaya ${ }^{3}$, Mehmet Ünlü ${ }^{4}$, Sinan

\begin{abstract}
Tibial fractures are encountered in various age-groups. Depending on fracture type and pattern, many types of treatment options including plate fixation, intramedullary fixation, circular external fixation are widely used. Depending on implant design, surgical approach and accompanying soft tissue conditions, success of these fractures could be various and be jeopardised. In this study, we wish to evaluate the benefits and side effects between plate and distal-wedge tibial nail fixation.

Between 2013 and 2016 (in Van Regional, Education and Research Hospital, Turkey) 38 patients (25 male, 13 female patients: ages range 18 to 61 years, mean age is 41) treated surgically using distal-wedge tibial nail fixation (amount:16) and plate fixation (amount:22). The patients were evaluated by AOFAS score (documentated 1.5 and 6 months postoperatively), postop hospitalisation days, perop fluouruscopy imaging (scopy shooting) times and union time (months). Average follow-up time was 11 months (range: 9 to 28 months).

There was a shorter recovery period in the nail group and the hospital stay was shorter. $(\mathrm{P}<0.001)$ The AOFAS score was higher at 1.5 months postoperatively and the number of scopies was higher at 1.5 months olds $(\mathrm{p}<0.001)$ No significant difference was found in postoperative 6th month AOFAS score between plate and nailing groups.

We have found and concluded that DSBLS (Distal Supportive Bolt Locking Screw) screw of this tibial nailing fixation system could provide distal interlocking strong enough especially when fracture is quite close to the distal tibial articular face, using distal wedge tibial nails and components.
\end{abstract}

Key Words: Tibia metaphysis fracture, plate, intramedullary nailing

\section{Introduction}

Tibia is the most encountered long human body bone with fracture by its anatomical relationship and localisation, and its properties make it expose to morbidity, prolonged hospital care and healing time (1). Looking through the literature, plate fixation, intramedullary nailing, circular external fixation (and very rarely cast bracing) has been used for tibial fracture stabilisation. The stability of the fracture and soft tissue damage must be balanced in order to obtain union with no or very little morbidity. Plate fixation (lesser when done percutaneously) causes fracture haematoma loss, periosteal damage, prolonged healing time and delay of full weight bearing by patients, more soft tissue problems. Nailing, especially for distal tibial fracture patterns, requires experience to have adequate positioning, distal interlocking and lower scopy shooting. Moreover, when the proximity of any long bone fractures to its joint ends, the more technical and surgical difficulty for fixation occurs and the postoperative complications are encountered more (Figure 1, Figure 2). For these and many other reasons, distal tibial metaphyseal stabilisation is still a serious and difficult problem for orthopedic surgeons to resolve and researches are still being performed multidirectionally $(2,3)$.

In this study, we hypothesised that distal-wedge tibial nailing using its DSBLS screw could be a better choice for distal tibial metaphyseal extraarticular fractures than plate fixation, especially when performed with closed manner. We wished to evaluate the efficiency, pros and cons of distal tibial stabilisation using DSLBS screw and distalwedge tibial nailing, which is proven previously for tibial shaft fracture fixation and shortened healing time (4). 


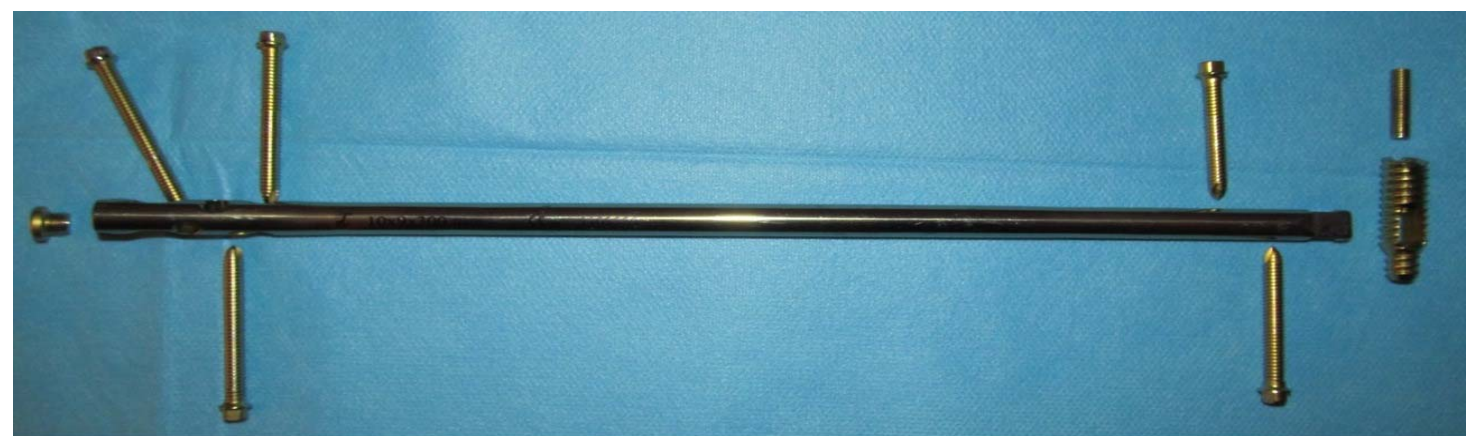

Fig. 1. Distal-Wedge Tibial Intramedullary Nail With DSBLS Screw. Note that distal interlocking screws (thicker than $10 \mathrm{~mm}$ and above nails) may be preffered. (In this study, we have used DSBLS screw to obtain distal interlocking).

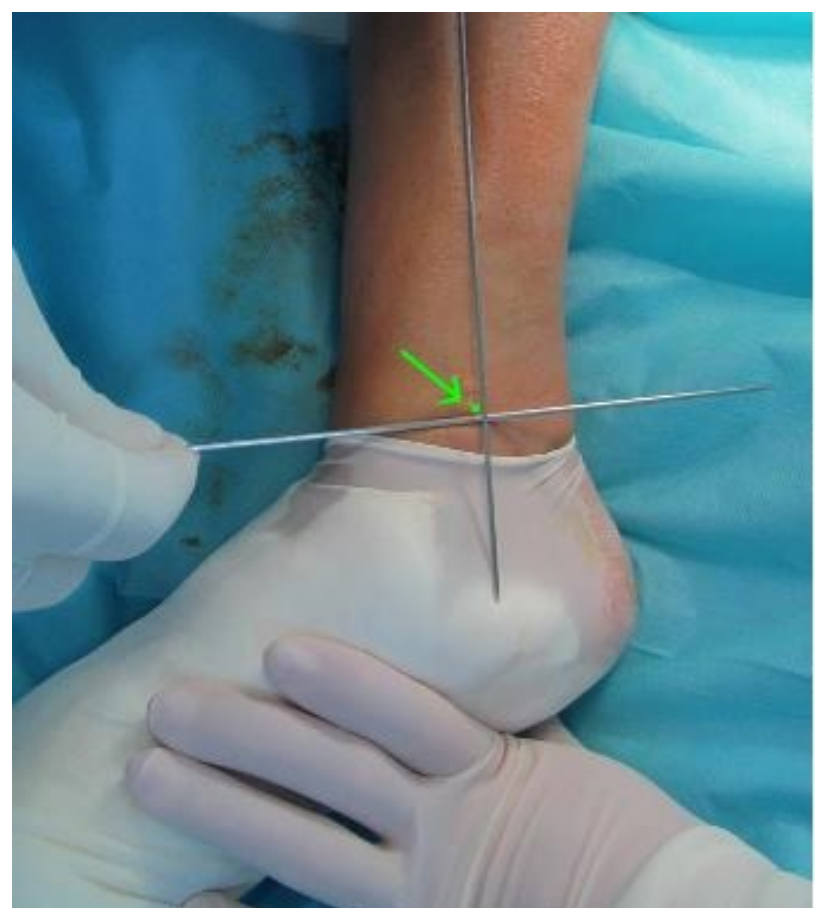

Fig. 2. Guide-wire insertion for drilling of DSLBS Screw (narrated on the text below).

\section{Materials and Methods}

Open and limited open (percutaneous) reduction and plate-fixation (22 patients)(Figure 3) and closed reduction and distal-wedge tibial nail with DSBLS screw-fixation (16 patients) (Figure 4) were included for this study. The fracture pattern has been chosen as extraa-articularly distal tibial metaphyseal region (AO-OTA classification is 43A1, 43A2 and 43A3 pattern), whose distances are determined above the pilon about 1.5 and $3 \mathrm{~cm}$. For plate fixation, Standard anterolateral or medial approach were used. For distally-wedged tibial nail fixation, standard proximal tibial minimal invasive approach (for nail insertion) by closed reduction of the fracture and distal and medial approach (for DSBLS screw insertion) were done. All surgical treatments have been performed by a team including any two of the surgeons in the same operating room. After surgery, most of the patients were continued bracing by short leg cast-splinting (plate group), in contrast; for nailing group it wasn't necessary. All

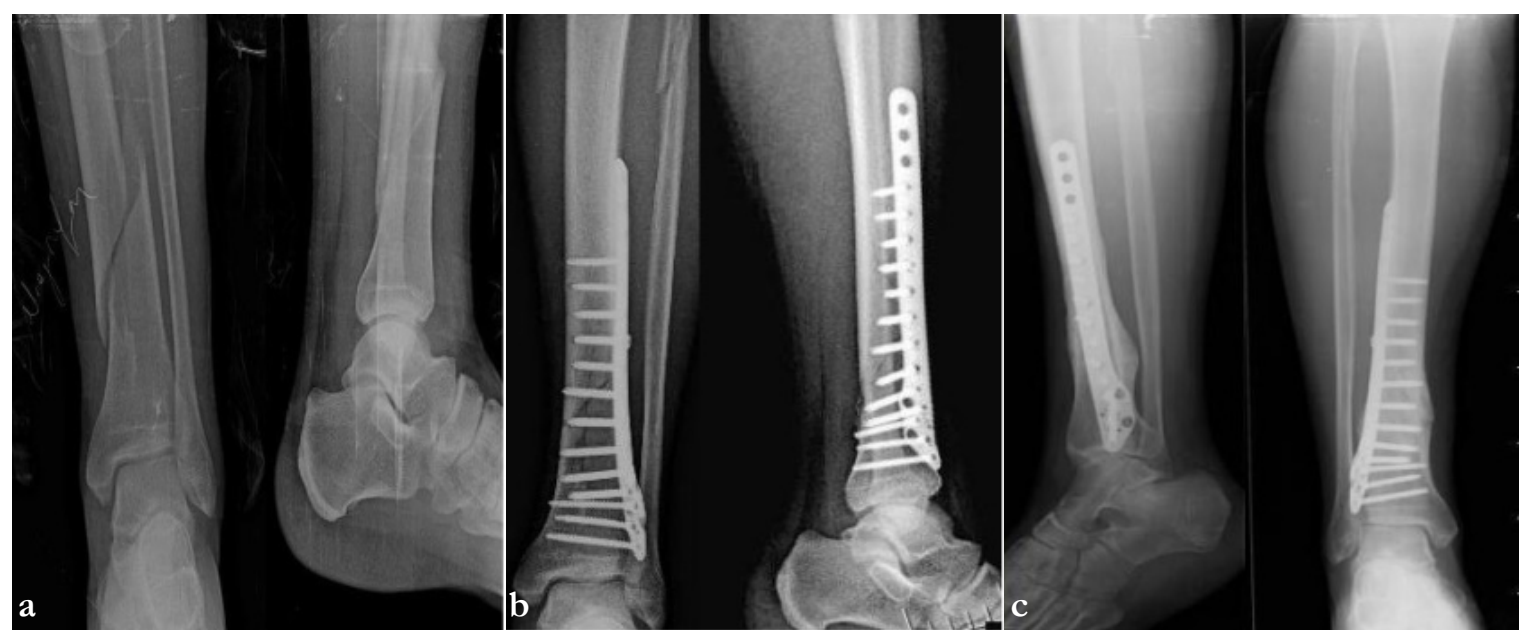

Fig. 3. Age: 30, Female, Fallen From Ladders, Proximity of Fracture Site to Pilon is $1.8 \mathrm{cms}$ long. (X-Rays; a: preoperative, b: postoperative, c: post-op $4^{\text {th }}$ month) 

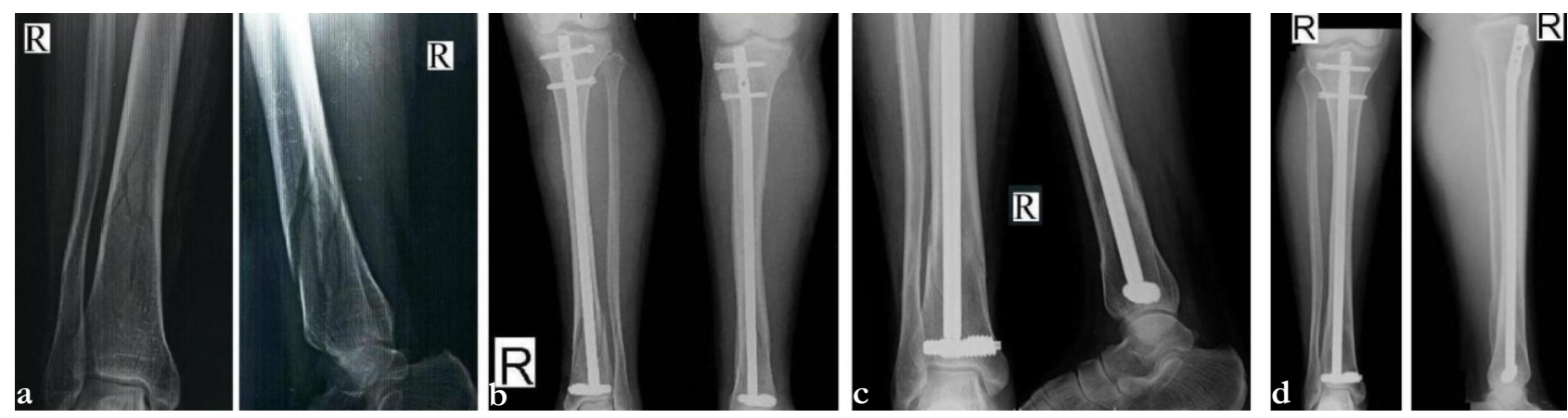

Fig. 4. Age: 41, Fallen while walking, cast-bracing was done in another centre 10 days ago, note the a fissure extends distally above $1.5 \mathrm{~cm}$ proximal to pilon. To stabilise fissure, a cannulated double-compression screw was used. (X-Rays; a: Preoperative, b: postoperative, c: Post-op $80^{\text {th }}$ day, d: Post-op $4^{\text {th }}$ Month)

patients were given cefazolin prophylaxis before and after surgery to prevent infective complications (mean time: 3 days-2 to 5 days interval), and enoxaparine for DVT (deep venous thrombosis) prophylaxis preoperatively and postoperatively (mean time: 15 days-10 to 20 days interval). Distal-wedge tibial nail was chosen for the study because its DSBLS screw (Distal Supportive Bolt Locking Screw), which could be used for distal interlocking alone, was proven that the screw itself could establish stable distal interlocking without any support and necessity for tibial fracture stabilisations (4). All patients have been evaluated using AOFAS score after $1.5^{\text {th }}$ month and $6^{\text {th }}$ months of surgery (5). Scopy has been used peroperavitely to evaluate reduction and screw and nail leng ${ }^{\text {th }}$. Tolerated weight bearing by patients (mild to full load-depending on patients' courage) has been allowed postoperatively and no brace has been used in the nailing group; while full weight bearing has not been allowed postoperatively about 1.5 months and short-leg cast bracing was used in the plate group. In this study, 16 patients have been treated using distal-wedge tibial nail, and 22 patients have been treated using distal anatomical tibial plate and screws between January-2013 and November2016. Patients have been followed about 2 years (range: 9 to 30 months). AOFAS scoring has been chosen for evaluating because this scoring system contains radiographic (like Stability), objective (like Alignment and Range Of Motion) and subjective (like Pain) criterias and combines them as a whole (5). Permission of this study was acquired from Van Region, Education and Research Hospital Clinical Researches Ethical Committee (decision number: 2016/1).

We preferred and used DSBLS screw insertion by scopy-aided free-hand method because of the approximity of the fracture line to pilon articular face. In this fashion, note that using image intensifier, position of the vertical $\mathrm{k}$-wire is centered to tibia and the anterior $1 / 3$ portion of medial malleolus, and position of the horizontal kwire is determined by distal extension of the fracture pattern. At just anterosuperior portion of the junctions of the k-wires, a $3 \mathrm{rd} \mathrm{k}$-wire is sent to distal tibial metaphysis parallel to both vertical and horizontal k-wires and superiorly and parallel to the pilon articular face. This is the most crucial and important stage of the operation and surgery team must be very cautious!!!. Via 3 rd k-wire (diameter must be $1.5 \mathrm{~mm}$ or lesser until $1.2 \mathrm{~mm}$ ), with scopy controls; skin incision about $1.5 \mathrm{~cm}$ is done and then, $5.0 \mathrm{~mm}$ cannulated drill is sent to tibia firstly. Secondly, the thicker $8 \mathrm{~mm}$ DSBLS cannulated drill (which is available in the application set) is sent slowly and cautiously. Mostly, we preferred to determine the length of DSBLS screw by a $4^{\text {th }} \mathrm{k}$-wire (all wires must be the same size) and the measurement of the outside length of thicker DSBLS drill inserted to tibia from the outer cortical face of tibia. The distinction is measured and the length is equal to the DSBLS screw length to be inserted mostly (rarely, we implanted 2 to $3 \mathrm{~mm}$ smaller or bigger DSBLS screw: scopy checking must be done after DSBLS implantation in order not to pass anterolateral portion of tibia and not to irritate distal tibiofibular joint or syndesmosis). As a result, scopy shooting is higher totally than plate group because of the accuracy of this stage.

Skin incision should be done meticulously and longitudinally around the $3 \mathrm{rd} \mathrm{k}$-wire. Because, just beneath the skin, saphenous vein is encountered mostly and could, and if possible, must be protected by gentle isolation.

For Plate fixation, standard anterolateral (open reduction) or medial approach (open or percutaneous) was performed depending on surgeons' experience and preference. All patients were given wound care routinely after discharging 
patients from hospital until soft tissue healing had ended, and sutures were removed in an outpatient visit.

\section{Results}

We have found statistically significant differences in "Postoperative $1.5^{\text {th }}$ Month AOFAS score" and "Scopy Shooting (Counts)" medians ( $p=0.039$ and $\mathrm{p}<0.001$, respectively) between plating and nailing group. Nailing group has higher "Postoperative $1.5^{\text {th }}$ month AOFAS Score" and "Scopy Shooting" means (Table 1 and Table 2).

There are significant differences between plating and nailing group in "Postoperative hospitalisation (days)" and "Union (month)" times medians $(p<0.0001)$. Nailing group has shorter times for both.

Table 1. Results of patients treated by nailing with DSBLS osteosynthesis

\begin{tabular}{|c|c|c|c|c|c|}
\hline $\begin{array}{l}\text { Patient } \\
\text { No }\end{array}$ & $\begin{array}{c}\text { Postoperative } 1.5^{\text {th }} \\
\text { month AOFAS } \\
\text { score }\end{array}$ & $\begin{array}{c}\text { Postoperative } 6^{\text {th }} \\
\text { month AOFAS } \\
\text { score }\end{array}$ & $\begin{array}{c}\text { Scopy } \\
\text { shooting } \\
\text { (Counts) }\end{array}$ & $\begin{array}{l}\text { Hospitalisation time } \\
\text { after surgery (Days) }\end{array}$ & $\begin{array}{l}\text { Union time } \\
\text { (Months) }\end{array}$ \\
\hline 1 & 79 & 89 & 24 & 2 & 3 \\
\hline 2 & 69 & 79 & 26 & 3 & 4 \\
\hline 3 & 72 & 87 & 16 & 2 & 3 \\
\hline 4 & 80 & 96 & 14 & 4 & 2 \\
\hline 5 & 98 & 100 & 14 & 2 & 2 \\
\hline 6 & 94 & 100 & 20 & 3 & 2 \\
\hline 7 & 90 & 96 & 20 & 2 & 2 \\
\hline 8 & 79 & 96 & 26 & 2 & 3 \\
\hline 9 & 97 & 100 & 12 & 3 & 2 \\
\hline 10 & 91 & 100 & 30 & 4 & 2 \\
\hline 11 & 81 & 96 & 26 & 2 & 2 \\
\hline 12 & 79 & 96 & 12 & 2 & 3 \\
\hline 13 & 76 & 94 & 20 & 2 & 4 \\
\hline 14 & 84 & 97 & 18 & 3 & 3 \\
\hline 15 & 84 & 94 & 16 & 4 & 3 \\
\hline 16 & 76 & 94 & 14 & 2 & 3 \\
\hline
\end{tabular}

Table 2. Results of patients treated by plate osteosynthesis

\begin{tabular}{|c|c|c|c|c|c|}
\hline Patient No & $\begin{array}{l}\text { Postoperative } 1.5^{\text {th }} \\
\text { month AOFAS } \\
\text { score }\end{array}$ & $\begin{array}{l}\text { Postoperative } 6^{\text {th }} \\
\text { month AOFAS } \\
\text { score }\end{array}$ & $\begin{array}{l}\text { Scopy } \\
\text { shooting } \\
\text { (Counts) }\end{array}$ & $\begin{array}{l}\text { Hospitalisation time } \\
\text { after surgery (Days) }\end{array}$ & $\begin{array}{l}\text { Union time } \\
\text { (Months) }\end{array}$ \\
\hline 1 & 52 & 86 & 6 & 4 & 6 \\
\hline 2 & 82 & 100 & 8 & 5 & 3 \\
\hline 3 & 58 & 84 & 6 & 4 & 6 \\
\hline 4 & 81 & 97 & 10 & 3 & 3 \\
\hline 5 & 81 & 100 & 10 & 4 & 3 \\
\hline 6 & 61 & 89 & 8 & 4 & 5 \\
\hline 7 & 81 & 100 & 12 & 5 & 3 \\
\hline 8 & 76 & 90 & 10 & 4 & 4 \\
\hline 9 & 81 & 94 & 8 & 4 & 3 \\
\hline 10 & 81 & 94 & 6 & 3 & 3 \\
\hline 11 & 44 & 72 & 10 & 4 & 6 \\
\hline 12 & 76 & 90 & 10 & 5 & 4 \\
\hline 13 & 56 & 79 & 8 & 4 & 3 \\
\hline 14 & 81 & 97 & 6 & 4 & 3 \\
\hline 15 & 81 & 97 & 8 & 4 & 5 \\
\hline 16 & 61 & 90 & 10 & 3 & 5 \\
\hline 17 & 29 & 61 & 12 & 5 & 6 \\
\hline 18 & 78 & 94 & 12 & 4 & 4 \\
\hline 19 & 81 & 90 & 14 & 4 & 3 \\
\hline 20 & 81 & 94 & 12 & 5 & 3 \\
\hline 21 & 81 & 97 & 14 & 4 & 3 \\
\hline 22 & 76 & 90 & 12 & 3 & 4 \\
\hline
\end{tabular}


No significant difference exists in "Postoperative $6^{\text {th }}$ Months AOFAS score" between plating and nailing group.

\section{Discussion}

Nail-osteosynthesis for distal tibial metaphyseal extra articular fracture using DSBLS Screw has more superiorities regarding postoperative early healing and mild to full load-bearing than plate osteosyntesis. On the other hand, this nailing system requires a bit more experience and more scopy shoot to obtain satisfactory reduction and distal interlocking because of distally position of the fractures. We think that localization of fracture site to metaphysis, protection of fracture haematoma, no soft tissue and periosteal damage, and load-sharing advantage of intramedullary fixation contribute to early healing, minimal or no Sudeck atrophy and joint stiffness, and mild to full load bearing (depending on patient's courage) and early better postoperative AOFAS score for the patients. None of our patients (both plate and nailing group) has delayed or non - union except In literature, many researches could be found about distal tibial stabilization (2,3,6-13). Also, intamedullary stabilization of tibial shaft fracture are investigated $(14,17)$. Interlocking, -especially distal level is still a great problem to arrange and to achieve $(7,18,20)$. Also, intramedullary fixation does not increase malunion and has advantages because of lesser soft tissue complications and closed manner (4). Reaming of intramedullary canal causes augmentations of bone-fixation material contact surface, intramedullary pressure, heat, possibility of mechanically bigger - diameter nail insertion and stability (4,21-23). As concerned, reaming has advantages such as possibility of insertion of thicker nail and increased stability and disadvantages like injury of reversible endosteal circulation and delay of fractures especially when fracture is placed diaphyseally. On the other hand, spongious or cancellous bone heals more faster than cortical bone because of its anatomical vascular supplying properties (25). Preservation of fracture haematoma, respectful surgery to soft tissueespecially periosteum around fracture site, proper fixation and surgical approach choice, fighting against infections peroperatively, micromovement of fracture site after stabilization contributes healing. Hyperbaric oxygen therapy for selected patients may contribute and experimental researches exist in the literature $(25,26)$.
In this study, we have observed that distal tibial metaphysis extra articular fracture stabilization using distal-wedge tibial nail is a great choice especially when done by closed methods because of protection of fracture haematoma, soft tissue and periosteum, and the spongious structure of this area. This method has lesser healing and hospitalization durations and higher AOFAS score at early postoperative time than plate fixation. We think that healing process ends and remodellization process continues for both bone and soft-tissue healing, so postoperative $6^{\text {th }}$ month AOFAS score isn't different statistically between plate and nailing group. The only disadvantages of nailing are more scopy exposure and more experience. Plate fixation has lesser scopy usage but may lead to soft tissue problems and causes delayed (but acceptable) healing period. Removing of plate and screws is also another problem because of many reasons like cold-fusion. Nailing may lead to anterior knee pain because of involvement of infrapatellar branch. So, for the last words: researches and newer designs about implant technologies are being continued because the more proximity of fracture site to articular surface, the more technical and mechanical difficulties of stable fixation and more and more scopy usage.

Conflict of Interest: The authors have no conflict and have accepted no interest before, during and after completion of this study.

\section{References}

1. Horne G, Iceton J, Twist J, Malony R. Disability following fractures of the tibial shaft. Orthopedics 1990; 13: 423-426.

2. Im GI, Tae SK. Distal metaphyseal fractures of tibia: a prospective randomized trial of closed reduction and intramedllary nail versus open reduction and plate and screws fixation. J Trauma 2005; 59: 1219-1223.

3. Janssen KW, Biert J, van Kampen A. Treatment of distal tibial fractures: plate versus nail: a retrospective outcome analysis of matched pairs of patients. Int Orthop 2007; 31: 709-714.

4. Küçükdurmaz F, Akpınar F, Saka G, Sağlam N, Ac1 C. A newly designed intramedullary nail with distal interlocking system for tibia fractures in adults-the clinical results. Turkish Journal of Trauma and Emergency Surgery 2012; 18: 243249.

5. Kitaoka HB, Alexander IJ, Adelaar RS, et al. Clinical rating systems for the ankle-hindfoot, midfoot, hallux, and lesser toes. Foot Ankle Int 1994; 15: 349-353. 
6. Goldhahn S, Moser R, Bigler R, Matter P. Treatment methods and outcomes of tibial shaft fractures in Switzerland. A prospective multicenter study of the Swiss AO. Swiss Surg 2000; 6: 315-322.

7. Yavuz U, Sökücü S, Demir B, et al. Comparison of intramedullary nail and plate fixation in distal tibia diaphyseal fractures close to the motrise. Turkish Journal of Trauma and Emergency Surgery 2014; 20: 189-193.

8. Fan CY, Chiang CC, Chuang TY, et al. Interlocking nails for displaced metaphyseal fractures of the distal tibia. Injury 2005; 36: 669674.

9. Whatling GM, Nokes LD. Literature review of current techniques for the insertion of distal screws into intramedullary locking nails. Injury 2006; 37: 109-119.

10. Schnettler R, Borner M, Soldner E. Results of interlocking nailing of distal tibial fractures. Unfallchirurg 1990; 93: 534-537.

11. Boenisch UW, de Boer PG, Journeaux SF. Unreamed intramedullary tibial nailing-fatigue oflocking bolts. Injury 1996; 27: 265-270.

12. Robinson CM, McLauchlan GJ, McLean IP, Court-Brown CM. Distal metaphyseal fractures of the tibia with minimal involvement ofthe ankle: classification and treatment by locked intramedullary nailing. J Bone Joint Surg Br 1995; 77: 781-787.

13. Mosheiff R, Safran O, Segal D, Liebergall M. The unreamed tibial nailing in the treatment of distal metaphyseal fractures. Injury 1999; 30: 83-90.

14. Hou T, Li Q, Luo F, et al. Controlled dynamization to enhance reconstruction capacity of tissue-engineered bone in healing critically sized bone defects: an in vivo study in goats. Tissue Eng Part A 2010; 16: 201-212.

15. Penzkofer R, Maier M, Nolte A, et al. Infuence of intramedullary nail diameter and locking mode on the stability of tibial shaft fracture fixation. Arch Orthop Trauma Surg 2009; 129: 525-531.

16. Bhandari M, Tornetta P 3rd, Sprague S, et al.Predictors of reoperation following operative management of fractures of the tibial shaft. J Orthop Trauma 2003; 17: 353-361.
17. Goldhahn S, Moser R, Bigler R, et al. Treatment methods and outcomes of tibial shaft fractures in Switzerland. A prospective multicenter study of the Swiss AO. Swiss Surg 2000; 6:315-322.

18. Gueorguiev B, Wähnert D, Albrecht D, et al. Effect on dynamic mechanical stability and interfragmentary movement of angle-stable locking of intramedullary nails in unstable distal tibia fractures: a biomechanical study. J Trauma 2011; 70: 358-365.

19. Kaspar K, Schell H, Seebeck P, et al. Angle stable locking reduces interfragmentary movements and promotes healing after unreamed nailing. Study of a displaced osteotomy model in sheep tibiae. J Bone Joint Surg Am 2005; 87: 2028-2037.

20. Schüller M, Weninger P, Tschegg E, et al. Micromotion at the fracture site after tibial nailing with four unreamed small-diameter nails--a biomechanical study using a distal tibia fracture model. J Trauma 2009; 66: 1391-1407.

21. Finkemeier CG, Schmidt AH, Kyle RF, Templeman DC, Varecka TF. A prospective, randomized study of intramedullary nails inserted with and without reaming for the treatment of open and closed fractures of the tibial shaft. J Orthop Trauma 2000; 14: 187-193.

22. Bonnevialle P, Bellumore Y, Foucras L, Hézard L, Mansat M. Tibial fracture with intact fbula treated by reamed nailing. Rev Chir Orthop Reparatrice Appar Mot 2000; 86: 29-37.

23. Heim D, Schlegel U, Perren SM. Intramedullary pressure in intramedullary nailing of the femur and tibia. Helv Chir Acta 1994; 60: 605-610.

24. McRae R, MD, Pocketbook of Orthopaedic and Fractures, 2008, Chapter 18. ISBN: 978-975-277182-186.

25. Grassmann JP, Schneppendahl J, Hakimi AR, et al. Hyperbaric oxygen therapy improves angiogenesis and bone formation in critical sized diaphyseal defects. J Orthop Res 2015; 33: 513 520 .

26. Kawada S, Wada E, Matsuda R, Ishii N. Hyperbaric hyperoxia accelerates fracture healing in mice. PLoS One 2013; 8: e72603. 